\title{
Lugano Classification Adult Non-Hodgkin Lymphoma by AJCC v8 Stage
}

National Cancer Institute

\section{Source}

National Cancer Institute. Lugano Classification Adult Non-Hodgkin Lymphoma by AJCC v8 Stage. NCI Thesaurus. Code C141158.

A staging system for adult non-Hodgkin lymphomas based on the Lugano classification criteria. This staging system does not apply to ocular adnexal lymphomas (are staged according to the classification for ocular adnexal lymphoma), pediatric non-Hodgkin lymphomas (are staged according to the St. Jude Children's Research Hospital staging system), primary cutaneous lymphomas (are staged according to the classification for primary cutaneous lymphoma), and multiple myelomas (are staged according to the classification for plasma cell myeloma). (from AJCC 8th Ed.) 